\title{
Remote Sensing for Palmer Amaranth (Amaranthus palmeri S. Wats.) Detection in Soybean (Glycine max (L.) Merr.)
}

\author{
John T. Sanders ${ }^{1}$, Eric A. L. Jones ${ }^{1}$ D, Robert Austin ${ }^{1}$, Gary T. Roberson ${ }^{2}$, Robert J. Richardson ${ }^{1}$ \\ and Wesley J. Everman ${ }^{1, *}$ \\ 1 Department of Crop and Soil Sciences, North Carolina State University, Raleigh, NC 27695-7620, USA; \\ john.sanders@partners.basf.com (J.T.S.); eajone22@ncsu.edu (E.A.L.J.); resaustin@ncsu.edu (R.A.); \\ rob_richardson@ncsu.edu (R.J.R.) \\ 2 Department of Biological and Agricultural Engineering, North Carolina State University, Raleigh, \\ NC 27695-7620, USA; gtrobers@ncsu.edu \\ * Correspondence: Wesley_Everman@ncsu.edu
}

\section{check for}

updates

Citation: Sanders, J.T.; Jones, E.A.L.; Austin, R.; Roberson, G.T.;

Richardson, R.J.; Everman, W.J.

Remote Sensing for Palmer Amaranth

(Amaranthus palmeri S. Wats.)

Detection in Soybean (Glycine max (L.)

Merr.). Agronomy 2021, 11, 1909.

https://doi.org/10.3390/

agronomy11101909

Academic Editor:

Belen Gallego-Elvira

Received: 21 August 2021

Accepted: 21 September 2021

Published: 23 September 2021

Publisher's Note: MDPI stays neutral with regard to jurisdictional claims in published maps and institutional affiliations.

Copyright: (c) 2021 by the authors Licensee MDPI, Basel, Switzerland. This article is an open access article distributed under the terms and conditions of the Creative Commons Attribution (CC BY) license (https:// creativecommons.org/licenses/by/ $4.0 /)$.

\begin{abstract}
Field studies were conducted in 2016 and 2017 to determine if multispectral imagery collected from an unmanned aerial vehicle (UAV) equipped with a five-band sensor could successfully identify Palmer amaranth (Amaranthus palmeri) infestations of various densities growing among soybeans (Glycine max [L.] Merr.). The multispectral sensor captures imagery from five wavebands: 475 (blue), 560 (green), 668 (red), 840 (near infrared [NIR]), and $717 \mathrm{~nm}$ (red-edge). Image analysis was performed to examine the spectral properties of discrete Palmer amaranth and soybean plants at various weed densities using these wavebands. Additionally, imagery was subjected to supervised classification to evaluate the usefulness of classification as a tool to differentiate the two species in a field setting. Date was a significant factor influencing the spectral reflectance values of the Palmer amaranth densities. The effects of altitude on reflectance were less clear and were dependent on band and density being evaluated. The near infrared (NIR) waveband offered the best resolution in separating Palmer amaranth densities. Spectral separability in the other wavebands was less defined, although low weed densities were consistently able to be discriminated from high densities. Palmer amaranth and soybean were found to be spectrally distinct regardless of imaging date, weed density, or waveband. Soybean exhibited overall lower reflectance intensity than Palmer amaranth across all wavebands. The reflectance of both species within blue, green, red, and red-edge wavebands declined as the season progressed, while reflectance in NIR increased. Near infrared and red-edge wavebands were shown to be the most useful for species discrimination and maintained their utility at most weed densities. Palmer amaranth weed densities were found to be spectrally distinct from one another in all wavebands, with greatest distinction when using the red, NIR and red-edge wavebands. Supervised classification in a two-class system was consistently able to discriminate between Palmer amaranth and soybean with at least $80 \%$ overall accuracy. The incorporation of a weed density component into these classifications introduced an error of $65 \%$ or greater into these classifications. Reducing the number of classes in a supervised classification system could improve the accuracy of discriminating between Palmer amaranth and soybean.
\end{abstract}

Keywords: remote sensing; weed management; species discrimination; UAV; multispectral

\section{Introduction}

Weeds can reduce soybean (Glycine max [L.] Merr.) yield by $\geq 50 \%$ if not controlled [1]. The complexity of weed management in soybean has increased with the evolution of herbicide-resistant weeds [2,3]. Palmer amaranth (Amaranthus palmeri S. Wats.) is a pervasive and ubiquitous weed in soybean and the difficulty in controlling the species is exacerbated by the evolution of resistance to most herbicides labeled for soybean $[4,5]$. Due to the already limited options for effective chemical control of Palmer amaranth and the 
potential for the evolution of additional herbicide resistance(s), site-specific weed management strategies have become necessary to reduce the amount of selection pressure exerted on weed populations [6-8].

Remote sensing research in soybean systems has been successful in identifying weed species via spectral characterization and has proven to be useful in performing speciesbased image classifications. Some of the earliest work involving remote sensing and soybean involved discriminating weed species from a soybean crop. Medlin et al. [9] was able to discriminate sicklepod (Senna obtusifolia L.) and pitted morningglory (Ipomoea lacunose L.) growing among soybean at densities of 10 plants $\mathrm{m}^{-2}$ with at least $85 \%$ accuracy. Additionally, Koger et al. [10] was able to discriminate with at least $90 \%$ accuracy weedy soybean patches from weed-free soybean patches. Gray et al. [11] analyzed the spectral properties of soybean along with six weed species and was able to perform a species-based supervised classification with varying degrees of accuracy. In a two-class system involving soybean and soil, a classification accuracy of $95 \%$ for soybean was achieved. When a weed category was introduced to this system, soybean classification accuracy dropped to between 77 and $80 \%$, suggesting that spectral similarity between soybean and weed species may introduce error into the classification process. Previous research conducted to identify wavebands useful for weed species discrimination in soybean found that areas between 490 and $500 \mathrm{~nm}$ and 600 and $700 \mathrm{~nm}$ within the visible range of the electromagnetic spectrum were proven to be useful for crop and weed discrimination [12-14].

Since remotely sensed imagery has proven useful in agronomic weed detection [6,15-17], it may be possible to utilize unmanned aerial vehicles (UAV) equipped with sensors to rapidly scout soybean fields to identify areas where Palmer amaranth is present. Unmanned aerial vehicles afford many benefits compared to traditional means of acquiring aerial imagery, due to their low cost, ease of use, and high spatial/temporal resolution [18,19]. Imagery acquired from these UAV platforms combined with image analysis tools may be able to provide a decision aid to farmers that would encourage site-specific agricultural practices. Such practices can reduce the total amount of herbicide being applied and the selection pressure being exerted on the weed populations [20]. These practices can also afford farmers diminished input and labor costs and provide sound environmental stewardship $[20,21]$.

Detection of Palmer amaranth in soybean relies on an understanding of the spectral reflectance of the two species, so research was conducted to determine if Palmer amaranth was spectrally distinct from soybean and to evaluate the potential for supervised classification for species discrimination. Furthermore, the spectral reflectance properties of Palmer amaranth and soybean plants were examined as a function of weed density, date, and flight altitude. In addition, the spectral behavior of different Palmer amaranth weed densities was explored across the same metrics to see if discrimination between Palmer amaranth densities was possible.

\section{Materials and Methods}

Experiments were established at three fields over two years at the Upper Coastal Plan Research Station near Rocky Mount, NC (35.89 N, -77.68 W) in 2016 and 2017. All experiments were planted with soybean (Asgrow AG5632) planted in rows $91.44 \mathrm{~cm}$ apart at a population of 321,000 seeds $\mathrm{ha}^{-1}$. Soybeans were planted in one field on 20 May 2016 and on 10 May and 19 June 2017 in two separate fields hereafter referred to as "B10" and "B8", respectively. The experimental design was a randomized complete block with four replications. Plots were $3.7 \mathrm{~m} \times 9.1 \mathrm{~m}$ in size and treatments consisted of different Palmer amaranth densities maintained throughout the season: 0,1,2,4, and 8 plants $\mathrm{m}^{-2}$. Glyphosate (408 $\mathrm{g}_{\text {ae }} \mathrm{ha}^{-1}$ ) was applied to the experiments to remove any weeds other than the natural population of glyphosate-resistant Palmer amaranth. The herbicide application was made using a $\mathrm{CO}_{2}$-pressurized backpack sprayer calibrated to a pressure of $207 \mathrm{kPa}$, delivering $140 \mathrm{~L} \mathrm{ha}^{-1}$ with TeeJet flat fan XR11002 nozzles (TeeJet 
Technologies Inc., Wheaton, IL 60187, USA,). Following herbicide application, plots were hand-weeded throughout the season to maintain the specific densities.

Aerial imagery was acquired over the study site across several dates using a UAV equipped with a multispectral sensor. The UAV platform consisted of an ATI AgBot (Aerial Technology International, Wilsonville, OR 97070, USA) fitted with a five-band multispectral sensor (MicaSense, Seattle, WA 98103, USA). The multispectral sensor acquires imagery from 20,20,10,40, and $10 \mathrm{~nm}$ bandwidths centered on wavelengths of 475 (blue; band 1), 560 (green; band 2), 668 (red; band 3), 840 (near infrared [NIR]; band 4), and $717 \mathrm{~nm}$ (red-edge; band 5), respectively (Table 1). The multispectral sensor has a focal length of $5.5 \mathrm{~mm}$, a horizontal field of view of $47.2^{\circ}$ and an image resolution of $1280 \times 960$ pixels. Ground spatial resolution for the multispectral sensor is $8.2 \mathrm{~cm}$ per pixel at $120 \mathrm{~m}$ altitude above ground level (AGL). Effort was made to only capture imagery on clear, cloudless days at approximately solar noon which could influence the image resolution across the different imaging dates.

Table 1. Wavebands captured by the multispectral sensor equipped on an unmanned aerial vehicle.

\begin{tabular}{cccc}
\hline Band Number & Band Name & Center Wavelength (nm) & Bandwidth (nm) \\
\hline 1 & Blue & 475 & 20 \\
2 & Green & 560 & 20 \\
3 & Red & 668 & 10 \\
4 & Near Infrared & 840 & 40 \\
5 & Red-Edge & 717 & 10 \\
\hline
\end{tabular}

In 2016, imagery was obtained from the Rocky Mount location on three dates: 14 July, 28 July and 12 August 2016. In 2017, imagery was obtained from the Rocky Mount location "B10" on 9 June, 27 June and 11 July 2017 and from the "B8" location on 6 July, 20 July, and 3 August 2017. On each date multispectral imagery was obtained at altitudes of 15,30 , and $45 \mathrm{~m}$ AGL. The sensor was calibrated via a reflectance panel before and after every flight to ensure radiometric integrity of the imagery. Raw imagery from every location and at each altitude was mosaicked using MicaSense ATLAS (MicaSense, Seattle, WA 98103, USA) and converted into a georeferenced Tagged Image File Format image (GeoTIFF). All spectral reflectance analysis and image classification was performed using ERDAS Imagine 2013 (Hexagon Geospatial US, Norcross, GA 30092, USA).

\subsection{Spectral Reflectance Measurements for Soybean and Palmer Amaranth}

Three samples of both soybean and Palmer amaranth were taken from each plot in the image for every image acquired. This procedure provided 60 spectral reflectance measurements per species for every image. Individual pixel measurements were favored over pixel neighborhood means to maintain the integrity of the samples and eliminate any effects of spectral mixing. The average of these three samples were used for analysis. These sample means were transformed via a square root function and subjected to analysis of variance using the MIXED procedure in SAS 9.4 (SAS Institute Inc., Cary, NC, USA) and means were separated using Tukey's HSD $(\alpha=0.10)$. Date, density, altitude and species were considered fixed effects with altitude being considered a nested factor within date. Replications were considered random effects. Preliminary analyses showed a significant band effect, so analysis of these spectral measurements occurred on a band basis.

\subsection{Spectral Measurements for Palmer Amaranth Weed Densities}

The spectral properties of soybean and Palmer amaranth were examined individually as a function of weed density and to examine the spectral reflectance of discrete Palmer amaranth population densities, mosaicked multispectral imagery was subjected to spectral analysis and subsequent image classification. Five rectangular area of interest (AOI) polygons were drawn within each of the experimental plots. These polygons were drawn as to encompass the edges of crop rows and the row middles which contained varying 
densities of Palmer amaranth. Area of interest polygons were generally uniform and covered at least 200 pixels. From within each of these AOI polygons, three mean reflectance value samples were randomly taken which contain reflectance information across all 5 bands of the multispectral imagery using the "Spectral Profile" tool in ERDAS Imagine 2013. These reflectance means included measurement for a user defined pixel neighborhood. For imagery from the $45 \mathrm{~m}$ altitude, a $3 \times 3$ pixel neighborhood was used for each of these samples, which represented a ground area of $150 \mathrm{~cm}^{2}$ per sample. This neighborhood size was increased to a $6 \times 6$ pixel neighborhood and a $12 \times 12$ neighborhood for imagery acquired from 30 and $15 \mathrm{~m}$, respectively, so as to maintain the same ground sampling area across every imaging altitude. As a result, 15 reflectance value means were acquired and averaged per plot, representing a total sampling size of 540, 2160, and 8640 pixels per treatment for imagery acquired at 45,30 , and $15 \mathrm{~m}$, respectively. The spectral reflectance for these pixel neighborhoods for the 5 bands was recorded and subjected to ANOVA using the MIXED procedure in SAS 9.4 (SAS Institute Inc., Cary, NC, USA) $(\alpha=0.10)$; wherein means were separated using Tukey's Honest Significant Difference $(\alpha=0.10)$. Treatment replications were considered a random effect while weed density, imaging date and altitude were considered fixed effects with altitude being considered a nested factor within date. Reflectance values were subject to a square root transformation to improve normality and reduce skewness in the data. Finally, because the bands of interest are highly disparate by nature and preliminary analysis showed an effect of band on reflectance, bands were analyzed separately for this procedure.

\subsection{Supervised Image Classification Methods}

Images were subjected to a two-class maximum likelihood supervised classification to discriminate soybean from Palmer amaranth (Figure 1). Fifteen training samples from throughout the image were gathered for both soybean and Palmer amaranth in addition to five training samples meant to delineate bare soil from vegetation using a maximum likelihood classification. Following classification, an accuracy assessment was performed on the supervised image to determine the accuracy at which the classifier was able to distinguish soybean and Palmer amaranth. A total of 100 test pixels, fifty for each species, were randomly generated throughout the image and were manually validated to be either soybean or Palmer amaranth. The manual validations were intended to either confirm or deny how a particular test pixel was classified. A pixel was deemed "correct" if a pixel was properly classified according to the species it represented in the pre-classified image; while an "incorrect" was recorded when a pixel of one of the species was classified as the other species. The accuracy assessment procedure was utilized to determine the producer's accuracy, user's accuracy, overall accuracy and kappa statistic (K) for each classification. User's accuracy is the proportion of the map accuracy from the point of view of a map user (i.e., the authors), producer's accuracy is the proportion of the map accuracy from the point of view of the map maker (i.e., the software), and overall accuracy is the proportion of reference sites mapped correctly. Finally, the kappa statistic (K), a measure of agreement between the reference image and the classifier, was computed for each classification. 

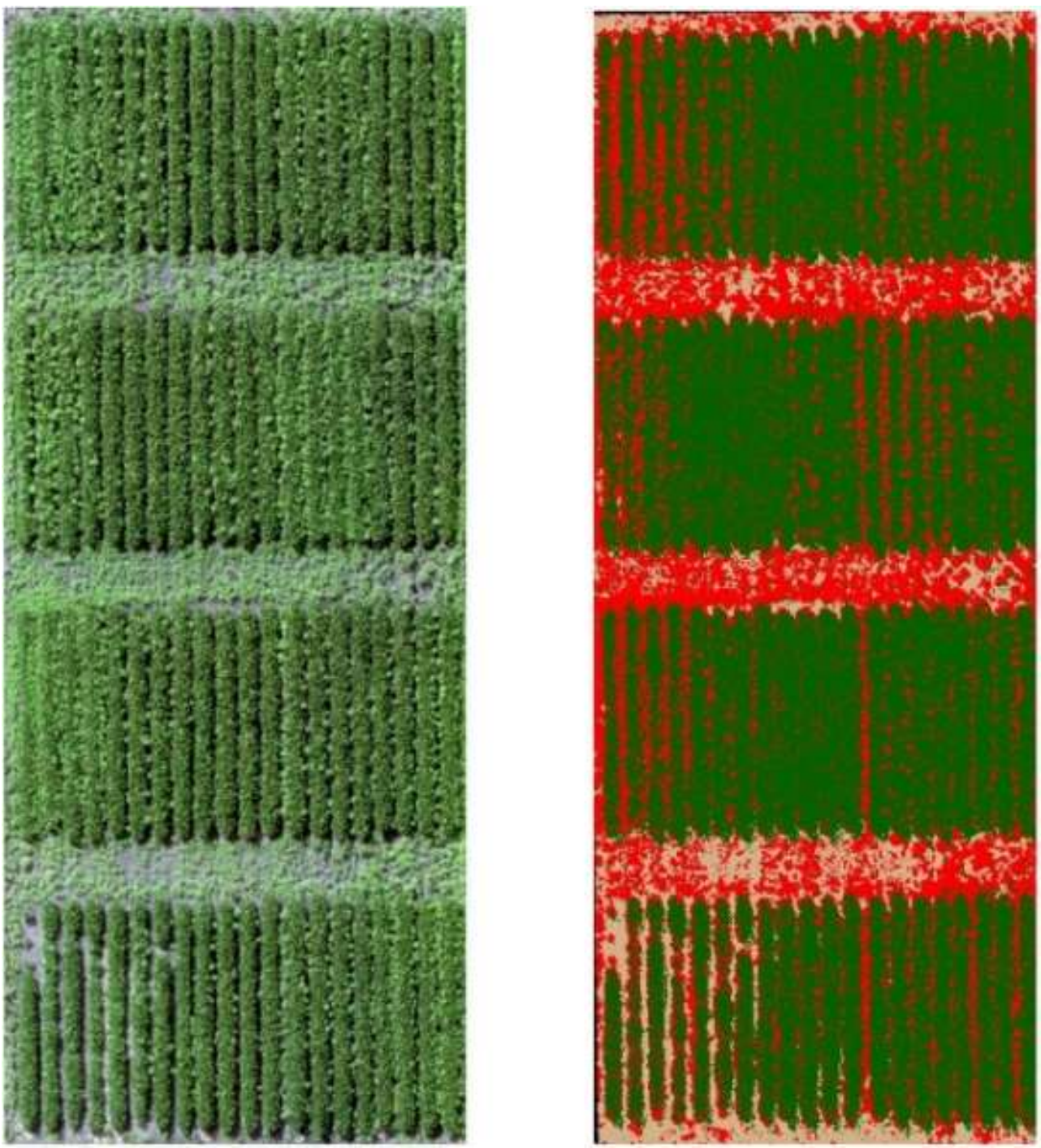

Figure 1. Comparison of a raw (left) and two-class classified image (right) of Palmer amaranth and soybeans growing in mixed stands. In the classified image, green represents soybean while red represents Palmer amaranth.

The multispectral imagery acquired at $15 \mathrm{~m}$ from all three studies was also subjected to an eight-class (soybean with the various Palmer amaranth densities) maximum likelihood supervised classification to determine if different Palmer amaranth weed densities could be discriminated among one another and soybean. The $15 \mathrm{~m}$ imagery from 28 July 2016 was not able to be used for this purpose as the original image file became corrupted. One replicate of four was chosen from each image to utilize as a training block while the remaining three were used as the test blocks to perform the supervised classification. In each plot in the first replicate, excluding the plots with a weed density of 0 plants $\mathrm{m}^{-2}$, seven samples each for Palmer amaranth and soybean were collected and grouped according to the weed density treatment. These training samples were meant to capture any effects of weed density on the spectral reflectance patterns of the two species and to refine the image classification. An accuracy assessment was then performed on the supervised imagery using 80 test points randomly generated throughout the image using a methodology identical to that of the two-class accuracy analysis. 


\section{Results and Discussion}

\subsection{Spectral Reflectance Patterns of Palmer Amaranth and Soybean \\ 3.1.1. Rocky Mount 2016}

All three experimental runs showed a significant date by species interaction across all wavebands, which suggests species discrimination via spectral reflectance may be influenced by temporal conditions. In addition, three-way interactions involving the main effects were detected and demonstrate the complex nature by which these factors influence spectral reflectance.

In 2016, two-way interactions involving date and species as well as species and altitude were significant across every waveband. Furthermore, a three-way interaction involving density, altitude, and species was significant for red, NIR, and red-edge wavebands. Date by species interaction influenced species reflectance values in 2016, with soybean reflectance values significantly lower in every waveband, for each date except for NIR waveband on the 28 July imaging date where the two species were spectrally similar. Reflectance values for both Palmer amaranth and soybean were different between imaging dates (Table 2).

Table 2. Spectral reflectance values of Palmer amaranth and soybean across dates and fields from aerial imagery collected from an altitude of $15 \mathrm{~m}$ at Rocky Mount, NC in 2016.

\begin{tabular}{|c|c|c|c|c|c|c|c|c|c|c|c|}
\hline \multirow{4}{*}{$\begin{array}{c}\text { Date } \\
\text { July }(14,6)\end{array}$} & \multirow{4}{*}{$\begin{array}{c}\text { Species } \\
\begin{array}{c}\text { Palmer amaranth } \\
\text { Soybean }\end{array}\end{array}$} & \multicolumn{10}{|c|}{ Waveband } \\
\hline & & \multicolumn{2}{|c|}{ Blue } & \multicolumn{2}{|c|}{ Green } & \multicolumn{2}{|c|}{ Red } & \multicolumn{2}{|c|}{ Near Infrared } & \multicolumn{2}{|c|}{ Red-Edge } \\
\hline & & 41 & ba & 73 & $\mathrm{~b}$ & 44 & $\mathrm{~b}$ & 160 & $\mathrm{~b}$ & 107 & $\mathrm{a}$ \\
\hline & & 28 & $\mathrm{e}$ & 52 & $\mathrm{~d}$ & 31 & $\mathrm{~d}$ & 149 & $\mathrm{~d}$ & 88 & c \\
\hline \multirow{2}{*}{ July $(28,20)$} & Palmer amaranth & 35 & $\mathrm{c}$ & 62 & $\mathrm{c}$ & 36 & $\mathrm{c}$ & 139 & $\mathrm{e}$ & 86 & $\mathrm{c}$ \\
\hline & Soybean & 25 & $\mathrm{f}$ & 43 & $\mathrm{e}$ & 25 & $\mathrm{e}$ & 137 & $\mathrm{e}$ & 72 & $\mathrm{e}$ \\
\hline \multirow{2}{*}{ August $(10,3)$} & Palmer amaranth & 44 & $\mathrm{a}$ & 76 & $\mathrm{e}$ & 47 & $\mathrm{e}$ & 168 & $\mathrm{a}$ & 102 & $\mathrm{~b}$ \\
\hline & Soybean & 32 & $\mathrm{~d}$ & 46 & $\mathrm{~d}$ & 31 & $\mathrm{~d}$ & 152 & c & 75 & $\mathrm{~d}$ \\
\hline
\end{tabular}

Similar letters within a column are not significantly different according to Tukey's HSD $(\alpha=0.10)$.

A significant species by altitude interaction demonstrated a decline in Palmer amaranth reflectance as altitude increased (Table 2). On 14 July, Palmer amaranth and soybean reflectance was significantly different across every waveband and at every altitude, with exceptions occurring in the 30 and $45 \mathrm{~m}$ imagery at a weed density of 1 plant $\mathrm{m}^{2}$ and in the $45 \mathrm{~m}$ imagery at weed densities of 2 plants $\mathrm{m}^{-2}$. In early season (June), the effect of altitude was significant for Palmer amaranth reflectance for NIR and red-edge wavebands, where a significant decrease in reflectance was observed with increasing altitude. By July 28 , the altitude effect had diminished, and the two species remained spectrally distinct for all wavebands except for the NIR waveband. On August 12, the effect of altitude became more pronounced than in the previous imaging dates, with significant altitude effects being observed for Palmer amaranth reflectance within green, red, NIR, and red-edge wavebands. As was the case for the July 14 imagery, Palmer amaranth and soybean differed significantly in their levels of reflectance at every altitude and waveband. The altitude effects observed on this date manifested as a significant decrease in Palmer amaranth as altitude increased for the NIR and red-edge wavebands. Soybean spectral reflectance significantly differed with respect to altitude only within red and NIR wavebands. Reflectance in the red waveband significantly increased with altitude while reflectance within NIR waveband significantly decreased at higher altitudes.

The three-way interaction between weed density, altitude, and species within date found for red, NIR, and red-edge wavebands demonstrated that the effect of weed density did not become apparent until later in the season as there was an absence of significance in weed density for the 14 July and 28 July imaging dates save for one instance. Additionally, any effects of weed density on species spectral reflectance appear to vary based on the species being observed. Reflectance in the red waveband was unaffected by weed 
density at all three imaging dates, but on 12 August, weed density affected the spectral reflectance values of Palmer amaranth and soybean in NIR and red-edge wavebands. Only the reflectance of Palmer amaranth in the NIR waveband significantly decreased when weed density increased. Reflectance within the red-edge waveband for both species was affected by a date dependent influence of weed density. On 28 July, only the reflectance of Palmer amaranth significantly increased when weed density increased. Soybean spectral reflectance in the red-edge waveband was significantly affected by weed density on 12 August, with significant decreases in reflectance when density increased from 1 to 4 plants $\mathrm{m}^{-2}$ at $15 \mathrm{~m}$. In addition, density $8 \mathrm{~m}^{-2}$ had significantly higher reflectance than the other weed densities at 30 and $45 \mathrm{~m}$ altitude on this date (Table 3 ).

Table 3. Influence of image date, Palmer amaranth density, and altitude on spectral reflectance values of Palmer amaranth and soybean in 2016.

\begin{tabular}{|c|c|c|c|c|c|c|c|c|c|c|c|}
\hline \multirow{2}{*}{ Date } & \multirow{2}{*}{$\begin{array}{l}\text { Weed Density } \\
\mathbf{m}^{-2}\end{array}$} & \multirow{2}{*}{$\begin{array}{l}\text { Altitude } \\
\text { (m) }\end{array}$} & \multirow{2}{*}{ Species } & \multicolumn{8}{|c|}{ Band } \\
\hline & & & & \multirow{2}{*}{$\begin{array}{c}\text { Blue } \\
40\end{array}$} & \multirow{2}{*}{$\begin{array}{c}\text { Green } \\
72\end{array}$} & \multicolumn{2}{|c|}{ Red } & \multicolumn{2}{|c|}{ Near Infrared } & \multicolumn{2}{|c|}{ Red-Edge } \\
\hline \multirow{24}{*}{14 July } & \multirow{6}{*}{1} & \multirow[b]{2}{*}{15} & Palmer amaranth & & & 42 & $f-i$ & 162 & $e-j$ & 107 & $a b c$ \\
\hline & & & Soybean & 27 & 51 & 29 & $\mathrm{p}-\mathrm{w}$ & 151 & o-t & 87 & $\mathrm{jkl}$ \\
\hline & & \multirow{2}{*}{30} & Palmer amaranth & 41 & 74 & 44 & $b-f$ & 159 & g-n & 107 & $\mathrm{abc}$ \\
\hline & & & Soybean & 28 & 51 & 30 & $o-u$ & 153 & $1-r$ & 88 & $\mathrm{jkl}$ \\
\hline & & \multirow{2}{*}{45} & Palmer amaranth & 41 & 71 & 44 & $b-f$ & 158 & h-o & 105 & b-e \\
\hline & & & Soybean & 28 & 52 & 31 & $\mathrm{o}-\mathrm{t}$ & 151 & o-t & 88 & $\mathrm{jkl}$ \\
\hline & \multirow{6}{*}{2} & \multirow[b]{2}{*}{15} & Palmer amaranth & 40 & 74 & 43 & $e-h$ & 163 & $\mathrm{~d}-\mathrm{i}$ & 108 & $\mathrm{ab}$ \\
\hline & & & Soybean & 26 & 50 & 28 & $r-x$ & 151 & o-t & 85 & $\mathrm{j}-\mathrm{n}$ \\
\hline & & \multirow[b]{2}{*}{30} & Palmer amaranth & 40 & 71 & 43 & def & 158 & h-o & 105 & bcd \\
\hline & & & Soybean & 27 & 51 & 30 & $\mathrm{p}-\mathrm{u}$ & 150 & $\mathrm{p}-\mathrm{t}$ & 86 & $j-m$ \\
\hline & & \multirow{2}{*}{45} & Palmer amaranth & 39 & 68 & 42 & e-i & 156 & $i-p$ & 101 & $c-g$ \\
\hline & & & Soybean & 30 & 53 & 32 & $n-t$ & 152 & $n-t$ & 89 & ijk \\
\hline & \multirow{6}{*}{4} & \multirow[b]{2}{*}{15} & Palmer amaranth & 40 & 74 & 44 & $b-f$ & 160 & $\mathrm{f}-1$ & 109 & $a b$ \\
\hline & & & Soybean & 30 & 54 & 31 & $\mathrm{o}-\mathrm{t}$ & 148 & $\mathrm{q}-\mathrm{u}$ & 88 & $\mathrm{jkl}$ \\
\hline & & \multirow[b]{2}{*}{30} & Palmer amaranth & 41 & 73 & 45 & $a-f$ & 161 & $\mathrm{e}-\mathrm{k}$ & 107 & $a b c$ \\
\hline & & & Soybean & 29 & 53 & 33 & $m-q$ & 147 & $q-v$ & 87 & $\mathrm{jkl}$ \\
\hline & & & Palmer amaranth & 41 & 72 & 44 & $c-f$ & 161 & $\mathrm{e}-\mathrm{k}$ & 106 & bcd \\
\hline & & 45 & Soybean & 28 & 51 & 31 & $m-q$ & 146 & $\mathrm{r}-\mathrm{w}$ & 86 & $j-m$ \\
\hline & & & Palmer amaranth & 40 & 76 & 43 & efg & 163 & $\mathrm{~d}-\mathrm{i}$ & 110 & $a b$ \\
\hline & & 15 & Soybean & 27 & 53 & 30 & $\mathrm{p}-\mathrm{v}$ & 147 & $q-v$ & 88 & $\mathrm{jkl}$ \\
\hline & & & Palmer amaranth & 43 & 79 & 48 & a-d & 161 & $\mathrm{e}-\mathrm{k}$ & 113 & a \\
\hline & 8 & 30 & Soybean & 28 & 55 & 31 & o-t & 148 & $\mathrm{q}-\mathrm{u}$ & 91 & hij \\
\hline & & & Palmer amaranth & 41 & 74 & 45 & $b-f$ & 157 & h-p & 107 & $a b c$ \\
\hline & & 45 & Soybean & 28 & 53 & 32 & $n-t$ & 145 & $s-x$ & 67 & $\mathrm{jkl}$ \\
\hline & & & Palmer amaranth & 34 & 58 & 34 & $1-q$ & 138 & xy & 82 & $1-q$ \\
\hline & & 30 & Soybean & 25 & 42 & 25 & $x^{1}$ & 140 & $v-y$ & 71 & uv \\
\hline & 1 & & Palmer amaranth & 34 & 60 & 35 & j-o & 139 & wxy & 84 & $\mathrm{k}-\mathrm{o}$ \\
\hline & & 45 & Soybean & 25 & 44 & 25 & wx & 138 & xy & 72 & tuv \\
\hline & & & Palmer amaranth & 34 & 60 & 35 & $\mathrm{j}-\mathrm{o}$ & 137 & xy & 83 & k-p \\
\hline & & 30 & Soybean & 25 & 43 & 25 & vwx & 137 & xy & 71 & tuv \\
\hline & 2 & & Palmer amaranth & 36 & 62 & 37 & $j-m$ & 140 & $u-y$ & 86 & $j-m$ \\
\hline 28 July & & 45 & Soybean & 26 & 44 & 25 & vwx & 139 & wxy & 73 & $\mathrm{~s}-\mathrm{V}$ \\
\hline & & & Palmer amaranth & 35 & 63 & 36 & $j-n$ & 141 & $\mathrm{u}-\mathrm{y}$ & 87 & $\mathrm{jkl}$ \\
\hline & & 30 & Soybean & 25 & 42 & 25 & vwx & 134 & $\mathrm{y}$ & 69 & $\mathrm{v}$ \\
\hline & 4 & & Palmer amaranth & 37 & 65 & 38 & i-1 & 141 & $u-y$ & 89 & ijk \\
\hline & & 45 & Soybean & 25 & 43 & 25 & $\mathrm{wx}$ & 136 & $\mathrm{y}$ & 72 & tuv \\
\hline & & & Palmer amaranth & 36 & 64 & 38 & h-k & 138 & xy & 88 & $\mathrm{jkl}$ \\
\hline & & 30 & Soybean & 26 & 44 & 26 & $u-x$ & 138 & xy & 72 & tuv \\
\hline & 8 & & Palmer amaranth & 36 & 65 & 38 & g-j & 138 & xy & 89 & ijk \\
\hline & & 45 & Soybean & 27 & 46 & 27 & $t-x$ & 137 & xy & 74 & $\mathrm{r}-\mathrm{V}$ \\
\hline
\end{tabular}


Table 3. Cont.

\begin{tabular}{|c|c|c|c|c|c|c|c|c|c|c|c|}
\hline \multirow{2}{*}{ Date } & \multirow{2}{*}{$\begin{array}{l}\text { Weed Density } \\
\mathbf{m}^{-2}\end{array}$} & \multirow{2}{*}{$\begin{array}{l}\text { Altitude } \\
\text { (m) }\end{array}$} & \multirow{2}{*}{ Species } & \multicolumn{8}{|c|}{ Band } \\
\hline & & & & \multirow{2}{*}{$\begin{array}{c}\text { Blue } \\
45\end{array}$} & \multirow{2}{*}{$\begin{array}{c}\text { Green } \\
78\end{array}$} & \multicolumn{2}{|c|}{ Red } & \multicolumn{2}{|c|}{ Near Infrared } & \multicolumn{2}{|c|}{ Red-Edge } \\
\hline \multirow{24}{*}{$\begin{array}{c}12 \\
\text { August }\end{array}$} & \multirow{6}{*}{1} & \multirow[b]{2}{*}{15} & Palmer amaranth & & & 45 & $a-f$ & 177 & $\mathrm{ab}$ & 106 & bcd \\
\hline & & & Soybean & 33 & 51 & 32 & $\mathrm{~m}-\mathrm{r}$ & 163 & $\mathrm{~d}-\mathrm{i}$ & 80 & $\mathrm{~m}-\mathrm{r}$ \\
\hline & & \multirow[b]{2}{*}{30} & Palmer amaranth & 44 & 74 & 47 & a-e & 171 & $b-d$ & 101 & $c-g$ \\
\hline & & & Soybean & 31 & 44 & 29 & $q-x$ & 148 & $\mathrm{q}-\mathrm{u}$ & 69 & $\mathrm{v}$ \\
\hline & & \multirow[b]{2}{*}{45} & Palmer amaranth & 41 & 71 & 43 & def & 164 & $c-i$ & 96 & gh \\
\hline & & & Soybean & 32 & 47 & 31 & $\mathrm{o}-\mathrm{u}$ & 148 & $\mathrm{q}-\mathrm{u}$ & 72 & $\mathrm{~S}-\mathrm{V}$ \\
\hline & \multirow{6}{*}{2} & \multirow{2}{*}{15} & Palmer amaranth & 47 & 79 & 49 & $\mathrm{a}$ & 183 & $\mathrm{a}$ & 108 & $\mathrm{ab}$ \\
\hline & & & Soybean & 29 & 43 & 25 & $x$ & 155 & $j-q$ & 71 & tuv \\
\hline & & \multirow{2}{*}{30} & Palmer amaranth & 43 & 72 & 46 & $a-f$ & 166 & $c-g$ & 98 & efg \\
\hline & & & Soybean & 33 & 49 & 32 & $\mathrm{n}-\mathrm{s}$ & 157 & $h-p$ & 77 & $\mathrm{p}-\mathrm{t}$ \\
\hline & & \multirow{2}{*}{45} & Palmer amaranth & 43 & 72 & 46 & $a-f$ & 164 & $\mathrm{c}-\mathrm{h}$ & 98 & $\mathrm{fg}$ \\
\hline & & & Soybean & 33 & 50 & 33 & $\mathrm{~m}-\mathrm{q}$ & 155 & $j-q$ & 77 & $\mathrm{o}-\mathrm{t}$ \\
\hline & \multirow{6}{*}{4} & \multirow{2}{*}{15} & Palmer amaranth & 46 & 79 & 48 & $a b c$ & 172 & $\mathrm{bc}$ & 107 & $a b c$ \\
\hline & & & Soybean & 34 & 49 & 34 & $\mathrm{k}-\mathrm{p}$ & 154 & $\mathrm{j}-\mathrm{r}$ & 76 & $q-u$ \\
\hline & & \multirow{2}{*}{30} & Palmer amaranth & 44 & 77 & 46 & $a-f$ & 169 & cde & 104 & $b-f$ \\
\hline & & & Soybean & 33 & 47 & 32 & $\mathrm{n}-\mathrm{r}$ & 152 & $\mathrm{n}-\mathrm{s}$ & 74 & $\mathrm{r}-\mathrm{v}$ \\
\hline & & \multirow{2}{*}{45} & Palmer amaranth & 40 & 70 & 43 & e-h & 160 & $g-m$ & 95 & ghi \\
\hline & & & Soybean & 29 & 43 & 28 & $S-X$ & 144 & $t-x$ & 69 & $\mathrm{~V}$ \\
\hline & \multirow{6}{*}{8} & \multirow{2}{*}{15} & Palmer amaranth & 45 & 82 & 48 & $\mathrm{ab}$ & 168 & $c-f$ & 108 & $\mathrm{ab}$ \\
\hline & & & Soybean & 30 & 46 & 30 & $\mathrm{p}-\mathrm{u}$ & 148 & $\mathrm{q}-\mathrm{u}$ & 73 & $S-V$ \\
\hline & & \multirow{2}{*}{30} & Palmer amaranth & 45 & 79 & 48 & $\mathrm{abc}$ & 166 & c-g & 105 & bcd \\
\hline & & & Soybean & 34 & 50 & 32 & $\mathrm{n}-\mathrm{s}$ & 152 & $\mathrm{~m}-\mathrm{r}$ & 78 & o-t \\
\hline & & \multirow{2}{*}{45} & Palmer amaranth & 42 & 75 & 48 & $\mathrm{ab}$ & 155 & $\mathrm{j}-\mathrm{q}$ & 99 & d-g \\
\hline & & & Soybean & 35 & 52 & 33 & $1-q$ & 154 & $\mathrm{k}-\mathrm{r}$ & 79 & $n-s$ \\
\hline
\end{tabular}

Similar letters within a column are not significantly different according to Tukey's HSD $(\alpha=0.10)$. Spectral reflectance values of Palmer amaranth and soybean were not different in the blue and green wavebands.

The effect of species plays a prominent role in these interactions, as Palmer amaranth and soybean remain spectrally distinct across all dates, weed densities and altitudes for the red and NIR wavebands. Across all main effects, the species remained spectrally distinct in the NIR waveband. Reflectance value differences between the two species was insignificant at weed densities between 1 and 4 plants $\mathrm{m}^{-2}$ in the 14 July imagery. In the later season imagery from 28 July and 12 August, spectral separation of the species was diminished at the highest weed density of 8 plants $\mathrm{m}^{-2}$ (Table 3 ).

\subsubsection{Rocky Mount 2017}

At the "B8" location in 2017 a two-way interaction involving species and date was significant for all wavebands. In addition, a three-way interaction involving date, density and species was significant for the NIR and red-edge bands. Palmer amaranth and soybean remained spectrally distinct, with soybean exhibiting lower reflectance than Palmer amaranth across every imaging date and waveband, excluding the NIR and red-edge waveband on 3 August and 6 July, respectively (Table 4). Reflectance of Palmer amaranth gradually declined throughout the season in blue and red wavebands but increased significantly between dates in the NIR waveband. Palmer amaranth reflectance in the green waveband increased in the mid-season imagery and remained at this intensity in the late season imagery. Palmer amaranth reflectance in the green waveband differed at every imaging date, while reflectance in red-edge waveband remained similar in early and late season imagery and the highest reflectance was observed in these bands on 20 July (Table 4). Soybean spectral reflectance was highest on the first imaging date of 6 July for blue, green, red, and red-edge wavebands. Soybean reflectance in blue and green wavebands decreased significantly between each imaging date. Soybean reflectance in the blue waveband was higher in the 6 July and 20 July imagery. Soybean reflectance in band two increased mid- 
season (20 July), but decreased by late-season (3 August) to levels significantly lower than those observed in the early-season imagery. As with Palmer amaranth, soybean spectral reflectance in the NIR waveband significantly increased through the season and reflectance values were highest on 3 August.

Table 4. Spectral reflectance values of Palmer amaranth and soybean across dates and weed densities from aerial imagery collected from an unmanned aerial vehicle at an altitude of $15 \mathrm{~m}$ at Rocky Mount, NC in 2017 (B8).

\begin{tabular}{|c|c|c|c|c|c|c|c|c|c|}
\hline \multirow{2}{*}{ Date } & \multirow{2}{*}{$\begin{array}{l}\text { Weed Density } \\
\mathbf{m}^{-2}\end{array}$} & \multirow{2}{*}{ Species } & \multicolumn{7}{|c|}{ Band } \\
\hline & & & \multirow{2}{*}{$\begin{array}{c}\text { Blue } \\
51\end{array}$} & \multirow{2}{*}{$\begin{array}{c}\text { Green } \\
76\end{array}$} & \multirow{2}{*}{$\begin{array}{c}\text { Red } \\
65\end{array}$} & \multicolumn{2}{|c|}{ Near Infrared } & \multicolumn{2}{|c|}{ Red-Edge } \\
\hline \multirow{8}{*}{6 July } & \multirow[b]{2}{*}{1} & Palmer amaranth & & & & 121 & $\mathrm{i}$ & 51 & $\mathrm{ab}$ \\
\hline & & Soybean & 41 & 71 & 49 & 128 & gh & 41 & de \\
\hline & \multirow[b]{2}{*}{2} & Palmer amaranth & 51 & 77 & 65 & 122 & $\mathrm{i}$ & 51 & $\mathrm{a}$ \\
\hline & & Soybean & 41 & 70 & 50 & 128 & gh & 41 & de \\
\hline & \multirow[b]{2}{*}{4} & Palmer amaranth & 52 & 77 & 64 & 125 & hi & 52 & $\mathrm{a}$ \\
\hline & & Soybean & 40 & 70 & 49 & 129 & gh & 40 & de \\
\hline & \multirow{2}{*}{8} & Palmer amaranth & 52 & 80 & 62 & 134 & $\mathrm{f}$ & 52 & $\mathrm{a}$ \\
\hline & & Soybean & 40 & 70 & 48 & 129 & gh & 40 & $\mathrm{e}$ \\
\hline \multirow{8}{*}{20 July } & \multirow[b]{2}{*}{1} & Palmer amaranth & 48 & 80 & 56 & 148 & $\mathrm{~d}$ & 48 & c \\
\hline & & Soybean & 34 & 59 & 38 & 140 & $\mathrm{e}$ & 43 & $\mathrm{fg}$ \\
\hline & \multirow[b]{2}{*}{2} & Palmer amaranth & 49 & 79 & 55 & 148 & $\mathrm{~d}$ & 49 & bc \\
\hline & & Soybean & 34 & 59 & 37 & 142 & $\mathrm{e}$ & 34 & $\mathrm{f}$ \\
\hline & \multirow[b]{2}{*}{4} & Palmer amaranth & 48 & 79 & 56 & 153 & $\mathrm{c}$ & 48 & c \\
\hline & & Soybean & 33 & 57 & 37 & 140 & $\mathrm{e}$ & 33 & $\mathrm{fg}$ \\
\hline & \multirow{2}{*}{8} & Palmer amaranth & 49 & 81 & 53 & 160 & $b$ & 49 & bc \\
\hline & & Soybean & 30 & 51 & 33 & 130 & $\mathrm{fg}$ & 30 & $\mathrm{~h}$ \\
\hline \multirow{8}{*}{3 August } & \multirow[b]{2}{*}{1} & Palmer amaranth & 42 & 72 & 43 & 162 & $\mathrm{ab}$ & 42 & de \\
\hline & & Soybean & 34 & 57 & 34 & 164 & $\mathrm{ab}$ & 34 & $\mathrm{fg}$ \\
\hline & \multirow[b]{2}{*}{2} & Palmer amaranth & 42 & 72 & 44 & 161 & $a b$ & 42 & $\mathrm{~d}$ \\
\hline & & Soybean & 34 & 56 & 34 & 165 & $\mathrm{a}$ & 34 & $\mathrm{fg}$ \\
\hline & \multirow[b]{2}{*}{4} & Palmer amaranth & 42 & 73 & 44 & 163 & $a b$ & 42 & $\mathrm{~d}$ \\
\hline & & Soybean & 33 & 57 & 34 & 165 & $\mathrm{a}$ & 33 & $\mathrm{fg}$ \\
\hline & \multirow{2}{*}{8} & Palmer amaranth & 42 & 73 & 43 & 163 & $a b$ & 42 & de \\
\hline & & Soybean & 32 & 56 & 32 & 163 & $a b$ & 32 & $\mathrm{~g}$ \\
\hline
\end{tabular}

Similar letters within a column are not significantly different according to Tukey's HSD $(\alpha=0.10)$. Spectral reflectance values of Palmer amaranth and soybean were not different in the blue, green, and red wavebands.

The three-way interaction between date, Palmer amaranth density and species observed in the NIR and red-edge waveband further elucidates the effect of temporal conditions. Regarding the NIR waveband, Palmer amaranth and soybean were spectrally distinct at each date and weed density except for 6 July and 3 August, when the two species were inseparable at every density (Table 5). On 6 July, Palmer amaranth reflectance in band 4 increased at a density of 8 plants $\mathrm{m}^{-2}$ compared to 1 plant and 4 plants $\mathrm{m}^{-2}$ densities (Table 5). Reflectance of soybean in the NIR waveband was unaffected by Palmer amaranth density on this date. On 20 July, Palmer amaranth reflectance in the NIR waveband increased with Palmer amaranth density, with reflectance significantly increasing between density groupings of 1, 2, 4, and 8 plants $\mathrm{m}^{-2}$. Palmer amaranth density began affecting soybean reflectance at this date; reflectance in the NIR waveband significantly decreased at the highest weed density of 8 plants $\mathrm{m}^{2}$ compared to every lower density. The 3 August imaging date revealed no effect of weed density on either Palmer amaranth or soybean spectral reflectance. 
Table 5. Spectral reflectance values of Palmer amaranth and soybean across dates from aerial imagery collected from an altitude of $15 \mathrm{~m}$ at Rocky Mount, NC in 2017 (B8).

\begin{tabular}{|c|c|c|c|c|c|c|c|c|c|c|c|}
\hline \multirow{2}{*}{ Date } & \multirow{2}{*}{ Species } & \multicolumn{10}{|c|}{ Band } \\
\hline & & \multicolumn{2}{|c|}{ Blue } & \multicolumn{2}{|c|}{ Green } & \multicolumn{2}{|c|}{ Red } & \multicolumn{2}{|c|}{ Near Infrared } & \multicolumn{2}{|c|}{ Red-Edge } \\
\hline \multirow{2}{*}{6 July } & Palmer amaranth & 51 & $\mathrm{a}$ & 78 & $\mathrm{~b}$ & 64 & $\mathrm{a}$ & 126 & $\mathrm{e}$ & 102 & $\mathrm{~b}$ \\
\hline & Soybean & 40 & $\mathrm{~d}$ & 70 & $\mathrm{~d}$ & 49 & c & 128 & $\mathrm{~d}$ & 101 & $\mathrm{~b}$ \\
\hline \multirow{2}{*}{20 July } & Palmer amaranth & 48 & $\mathrm{~b}$ & 80 & $\mathrm{a}$ & 55 & $\mathrm{~b}$ & 152 & $\mathrm{~b}$ & 111 & $\mathrm{a}$ \\
\hline & Soybean & 33 & $\mathrm{e}$ & 57 & $\mathrm{e}$ & 36 & $\mathrm{e}$ & 138 & c & 91 & $\mathrm{~d}$ \\
\hline \multirow{2}{*}{3 August } & Palmer amaranth & 42 & c & 73 & c & 43 & $\mathrm{~d}$ & 162 & $\mathrm{a}$ & 102 & $\mathrm{~b}$ \\
\hline & Soybean & 33 & $\mathrm{e}$ & 56 & $\mathrm{e}$ & 34 & $\mathrm{f}$ & 164 & $\mathrm{a}$ & 94 & c \\
\hline
\end{tabular}

Similar letters within a column are not significantly different according to Tukey's HSD $(\alpha=0.10)$.

The influence of the date, density and species interaction on reflectance in the rededge waveband demonstrated fewer differences than the NIR waveband. Soybean and Palmer amaranth remained spectrally distinct across each date and weed density, and soybean featured lower levels of reflectance compared to Palmer amaranth (Table 5). At the "B8" location, 20 July was the only imaging date where weed density effects on spectral reflectance were observed and only soybean reflectance was influenced. Reflectance of soybean in the red-edge waveband decreased significantly only at a weed density of 8 plants $\mathrm{m}^{-2}$ compared to densities of 1,2 , and 4 plants $\mathrm{m}^{-2}$.

At the 'B10" location in 2017, an interaction between date and species was significant in all wavebands. For green and red-edge wavebands, an additional interaction between date, Palmer amaranth density and species was found to be significant. Regardless of date effects, soybean and Palmer amaranth remained spectrally distinct in all wavebands for every date excluding band 4 on 9 June 2017 (Table 6). Palmer amaranth reflectance in the blue waveband significantly decreased in the mid-season imagery (27 June) and remained at this level in the season-end imagery (11 July) (Table 6). The reflectance of both species in the red waveband significantly declined throughout the season while reflectance in the NIR waveband increased significantly between each imaging date. Reflectance of Palmer amaranth in the red-edge waveband increased throughout the season while soybean reflectance was statistically greatest in the mid-season imagery from 27 June.

Table 6. Spectral reflectance values of Palmer amaranth and soybean across dates and Palmer amaranth densities from aerial imagery collected from an unmanned aerial vehicle at an altitude of $15 \mathrm{~m}$ at Rocky Mount, NC in 2017 (B10).

\begin{tabular}{|c|c|c|c|c|c|c|c|c|c|c|c|}
\hline \multirow{4}{*}{$\begin{array}{l}\text { Date } \\
9 \text { June }\end{array}$} & \multirow{4}{*}{$\begin{array}{c}\text { Species } \\
\begin{array}{c}\text { Palmer amaranth } \\
\text { Soybean }\end{array}\end{array}$} & \multicolumn{10}{|c|}{ Band } \\
\hline & & \multicolumn{2}{|c|}{ Blue } & \multicolumn{2}{|c|}{ Green } & \multicolumn{2}{|c|}{ Red } & \multicolumn{2}{|c|}{ Near Infrared } & \multicolumn{2}{|c|}{ Red-Edge } \\
\hline & & 45 & $\mathrm{a}$ & 69 & $b$ & 55 & $\mathrm{a}$ & 106 & $\mathrm{e}$ & 89 & c \\
\hline & & 35 & $\mathrm{c}$ & 58 & $\mathrm{~d}$ & 42 & $\mathrm{C}$ & 108 & $\mathrm{e}$ & 83 & $\mathrm{~d}$ \\
\hline \multirow{2}{*}{27 June } & Palmer amaranth & 43 & $\mathrm{~b}$ & 79 & a & 48 & $\mathrm{~b}$ & 151 & $\mathrm{~d}$ & 109 & a \\
\hline & Soybean & 34 & $\mathrm{c}$ & 64 & c & 37 & $\mathrm{~d}$ & 159 & $\mathrm{c}$ & 103 & $\mathrm{~b}$ \\
\hline \multirow{2}{*}{11 July } & Palmer amaranth & 44 & $\mathrm{~b}$ & 78 & $\mathrm{a}$ & 42 & c & 173 & $\mathrm{a}$ & 112 & $\mathrm{a}$ \\
\hline & Soybean & 29 & $\mathrm{~d}$ & 50 & $\mathrm{e}$ & 27 & $\mathrm{e}$ & 164 & $\mathrm{~b}$ & 88 & C \\
\hline
\end{tabular}

Similar letters within a column are not significantly different according to Tukey's HSD $(\alpha=0.10)$.

A significant interaction among date, density, and species within the green and rededge wavebands was observed for spectral reflectance levels of Palmer amaranth and soybean at various Palmer amaranth densities. Soybean reflectance was not significantly affected by changes in Palmer amaranth density, but Palmer amaranth reflectance values did begin to change with respect to weed density from mid-season (27 June) forward. On the 9 June imaging date, soybean had significantly lower reflectance in the green waveband compared to Palmer amaranth at every Palmer amaranth density (Table 7). On June 27, soybean continued to feature significantly lower reflectance than Palmer amaranth and density effects on Palmer amaranth reflectance began to become apparent with Palmer 
amaranth reflectance in the green waveband increasing at a weed density of 8 plants $\mathrm{m}^{-2}$ compared to 2 and 4 plants $\mathrm{m}^{-2}$. The 11 July imaging date featured a similar patternsoybean reflectance was significantly less than Palmer amaranth in the green waveband, and Palmer amaranth reflectance increased with increasing weed density. Reflectance of Palmer amaranth was significantly higher at densities of 4-8 plants $\mathrm{m}^{-2}$ compared to $1-2$ plants $\mathrm{m}^{-2}$. Palmer amaranth and soybean were spectrally distinct in the red-edge waveband at every imaging date and weed density except for a density of $1 \mathrm{plant}^{-2}$ on June 9 and densities of 2 and 4 plants $\mathrm{m}^{-2}$ on 27 June. In the red-edge waveband, reflectance of soybean was unaffected by weed density regardless of imaging date, but for all three imaging dates, Palmer amaranth reflectance did increase with increasing weed density.

Table 7. Spectral reflectance values of Palmer amaranth and soybean across dates and Palmer amaranth densities from aerial imagery collected from an unmanned aerial vehicle at an altitude of $15 \mathrm{~m}$ at Rocky Mount, NC in 2017 (B10).

\begin{tabular}{|c|c|c|c|c|c|c|c|c|c|}
\hline \multirow[b]{2}{*}{ Date } & \multirow{2}{*}{ 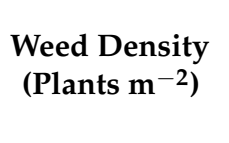 } & \multirow{2}{*}{ Species } & \multicolumn{7}{|c|}{ Band } \\
\hline & & & \multirow{2}{*}{$\begin{array}{r}\text { Blue } \\
45\end{array}$} & \multicolumn{2}{|c|}{ Green } & \multirow{2}{*}{$\begin{array}{c}\text { Red } \\
56\end{array}$} & \multirow{2}{*}{$\begin{array}{c}\begin{array}{c}\text { Near } \\
\text { Infrared }\end{array} \\
101\end{array}$} & \multicolumn{2}{|c|}{ Red-Edge } \\
\hline \multirow{8}{*}{9 June } & \multirow[b]{2}{*}{1} & Palmer amaranth & & 66 & def & & & 85 & fgh \\
\hline & & Soybean & 35 & 58 & $\mathrm{~g}$ & 42 & 108 & 84 & $\mathrm{gh}$ \\
\hline & \multirow{2}{*}{2} & Palmer amaranth & 46 & 70 & def & 56 & 106 & 90 & ef \\
\hline & & Soybean & 36 & 59 & $\mathrm{~g}$ & 44 & 107 & 83 & $\mathrm{~h}$ \\
\hline & \multirow[b]{2}{*}{4} & Palmer amaranth & 46 & 69 & de & 56 & 107 & 89 & efg \\
\hline & & Soybean & 34 & 58 & $\mathrm{~g}$ & 41 & 106 & 82 & $\mathrm{~h}$ \\
\hline & \multirow[b]{2}{*}{8} & Palmer amaranth & 45 & 70 & $\mathrm{~cd}$ & 54 & 111 & 92 & $\mathrm{e}$ \\
\hline & & Soybean & 34 & 58 & $\mathrm{~g}$ & 40 & 111 & 85 & fgh \\
\hline \multirow{8}{*}{27 June } & \multirow[b]{2}{*}{1} & Palmer amaranth & 44 & 78 & $\mathrm{ab}$ & 49 & 151 & 109 & $\mathrm{bc}$ \\
\hline & & Soybean & 35 & 64 & $\mathrm{f}$ & 38 & 159 & 102 & $\mathrm{~d}$ \\
\hline & \multirow[b]{2}{*}{2} & Palmer amaranth & 42 & 77 & $\mathrm{~b}$ & 48 & 149 & 107 & $\mathrm{~cd}$ \\
\hline & & Soybean & 35 & 64 & ef & 38 & 157 & 103 & $\mathrm{~d}$ \\
\hline & \multirow[b]{2}{*}{4} & Palmer amaranth & 42 & 77 & $\mathrm{~b}$ & 46 & 150 & 108 & bcd \\
\hline & & Soybean & 34 & 64 & $\mathrm{f}$ & 37 & 150 & 103 & $\mathrm{~d}$ \\
\hline & \multirow[b]{2}{*}{8} & Palmer amaranth & 44 & 82 & a & 48 & 156 & 113 & $a b$ \\
\hline & & Soybean & 34 & 63 & $\mathrm{f}$ & 36 & 161 & 103 & $\mathrm{~d}$ \\
\hline \multirow{8}{*}{11 July } & \multirow{2}{*}{1} & Palmer amaranth & 42 & 74 & $\mathrm{bc}$ & 40 & 171 & 108 & bcd \\
\hline & & Soybean & 29 & 49 & $\mathrm{~h}$ & 27 & 163 & 87 & efgh \\
\hline & \multirow[b]{2}{*}{2} & Palmer amaranth & 43 & 74 & $\mathrm{~b}$ & 41 & 170 & 107 & $\mathrm{~cd}$ \\
\hline & & Soybean & 30 & 52 & $\mathrm{~h}$ & 29 & 166 & 90 & ef \\
\hline & \multirow[b]{2}{*}{4} & Palmer amaranth & 46 & 82 & a & 43 & 178 & 116 & $\mathrm{a}$ \\
\hline & & Soybean & 29 & 50 & $\mathrm{~h}$ & 26 & 164 & 87 & efgh \\
\hline & \multirow[b]{2}{*}{8} & Palmer amaranth & 45 & 82 & a & 43 & 174 & 117 & a \\
\hline & & Soybean & 29 & 50 & $\mathrm{~h}$ & 27 & 165 & 88 & efgh \\
\hline
\end{tabular}

Similar letters within a column are not significantly different according to Tukey's HSD $(\alpha=0.10)$. Spectral reflectance values of Palmer amaranth and soybean were not different in the blue, red, and near infrared wavebands.

Regarding the date by species interaction present across all these studies, several conclusions can be made. The first is that reflectance significantly changes as the season progresses for both species across all bands. This trend is supported by the fact that reflectance in the NIR waveband continuously increased throughout the season while the reflectance levels of the blue, green, red, and red-edge wavebands were lower in later imaging dates than they were in early imaging dates for both species. This finding is rather unsurprising, given that the NIR waveband occupies a range of the electromagnetic spectrum known for its usefulness as an indicator of vegetative vigor. Thorp and Tian [22] discuss the ability of NIR light to quantify vegetative vigor and biomass with good accuracy. The marked increase in band 4 reflectance observed through these studies is a continuation of a long-held belief that light from within this region of the electromagnetic spectrum confers information regarding vegetative biomass and vigor. What remains to be concluded 
is if the declines in reflectance observed for the blue, green, red, and red-edge bands are the result of a real numerical decrease in reflectance from within these wavebands, or a decrease in each constituent proportion of overall reflected light represented by a particular waveband.

In examining the three-way interaction involving date, density and species, it can be concluded that Palmer amaranth and soybean remain spectrally distinct regardless of imaging date, weed density and waveband, with rare exception. The spectral differences between the species can be suggested that the internal physiology and architecture of Palmer amaranth and soybean could enable spectral separability [22]. While all wavebands were useful for discrimination between Palmer amaranth and soybean, the NIR and rededge wavebands were the most descriptive when reflectance changes in Palmer amaranth and soybean occurred due to surrounding Palmer amaranth density.

\subsection{Supervised Classification for Palmer Amaranth and Soybean Discrimination}

The two-class supervised classification system was successful in discriminating between Palmer amaranth and soybean from the multispectral imagery collected in 2016. Overall classification accuracies ranged from 69 to $90 \%$ and were able to classify the imagery with $\geq 80 \%$ overall accuracy in 2016 (Table 8). Imaging date or altitude did not demonstrate a consistent influence on overall classification accuracy, but by late season (August), some altitude effects were evident (Table 8). Altitude did not influence overall classification accuracy for 2016 imaging dates. Overall classification accuracies were the highest on the first imaging date (14 July) where accuracy was at least $78 \%$. As the season progressed, declines in accuracy were observed with the July 28 and August 12 imaging dates conferring accuracies $\geq 74 \%$ and $\geq 72 \%$, respectively.

Table 8. Summary of the two-class supervised classification accuracies for Palmer amaranth and soybean detection growing in mixed stands from aerial imagery collected from different altitudes at two separate fields at Rocky Mount, NC in 2016 and 2017.

\begin{tabular}{|c|c|c|c|c|c|c|c|c|}
\hline \multirow{2}{*}{ Field } & \multirow{2}{*}{ Date } & \multirow{2}{*}{ Altitude (m) } & \multicolumn{2}{|c|}{ Palmer Amaranth } & \multicolumn{2}{|c|}{ Soybean } & \multirow{2}{*}{$\begin{array}{l}\text { Overall Accuracy } \\
(\%)\end{array}$} & \multirow{2}{*}{ Kc } \\
\hline & & & $\mathbf{U A}^{\mathbf{a}}$ & PA & UA & PA & & \\
\hline \multirow{17}{*}{ B8 } & \multirow{3}{*}{ 14-July-16 } & 15 & 76 & 88 & 90 & 79 & 83 & 0.66 \\
\hline & & 30 & 64 & 89 & 92 & 72 & 78 & 0.56 \\
\hline & & 45 & 72 & 92 & 94 & 77 & 83 & 0.66 \\
\hline & \multirow{2}{*}{ 28-July-16 } & 30 & 72 & 92 & 94 & 88 & 83 & 0.66 \\
\hline & & 45 & 56 & 88 & 92 & 67 & 74 & 0.48 \\
\hline & \multirow{3}{*}{ 12-August-16 } & 15 & 86 & 94 & 94 & 87 & 90 & 0.80 \\
\hline & & 30 & 50 & 89 & 94 & 65 & 72 & 0.44 \\
\hline & & 45 & 56 & 90 & 94 & 68 & 75 & 0.50 \\
\hline & \multirow{4}{*}{ 6-July-17 } & 15 & 82 & 65 & 56 & 76 & 69 & 0.38 \\
\hline & & 30 & 92 & 82 & 80 & 91 & 86 & 0.72 \\
\hline & & 45 & 82 & 80 & 80 & 82 & 81 & 0.62 \\
\hline & & 15 & 88 & 73 & 68 & 85 & 78 & 0.56 \\
\hline & \multirow[t]{3}{*}{ 20-July-17 } & 30 & 80 & 83 & 84 & 81 & 82 & 0.64 \\
\hline & & 45 & 78 & 87 & 88 & 80 & 83 & 0.66 \\
\hline & & 15 & 74 & 93 & 94 & 78 & 84 & 0.68 \\
\hline & \multirow[t]{2}{*}{ 3-August-17 } & 30 & 90 & 83 & 82 & 89 & 86 & 0.72 \\
\hline & & 45 & 62 & 78 & 82 & 68 & 72 & 0.44 \\
\hline \multirow{9}{*}{$\mathrm{B} 10$} & \multirow{3}{*}{ 9-June-17 } & 15 & 84 & 78 & 76 & 83 & 80 & 0.60 \\
\hline & & 30 & 78 & 77 & 76 & 78 & 77 & 0.54 \\
\hline & & 45 & 86 & 77 & 74 & 84 & 80 & 0.60 \\
\hline & \multirow[t]{2}{*}{ 27-June-17 } & 15 & 82 & 84 & 84 & 82 & 83 & 0.66 \\
\hline & & 30 & 72 & 92 & 94 & 77 & 83 & 0.66 \\
\hline & \multirow{4}{*}{ 11-July-17 } & 45 & 68 & 87 & 94 & 74 & 79 & 0.58 \\
\hline & & 15 & 82 & 93 & 94 & 84 & 88 & 0.76 \\
\hline & & 30 & 82 & 91 & 92 & 84 & 87 & 0.74 \\
\hline & & 45 & 74 & 93 & 94 & 78 & 84 & 0.68 \\
\hline
\end{tabular}

a Abbreviations: UA, user's accuracy; PA, producer's accuracy; Kc, overall kappa statistic. 
The two-class supervised classification system was as successful in discriminating between Palmer amaranth and soybean from the multispectral imagery collected in 2017 from both fields. Overall accuracies for 2017 ranged from 69 to 88\% with certain classifications exceeding 80\% accuracy (Table 8). At the "B8" location, accuracy was increased in the 30 and $45 \mathrm{~m}$ imagery only on the 6 July and 20 July 2017 imaging dates. Regardless of altitude, overall classification accuracy was at least $69 \%$ at the "B8" location. Similar classification accuracies were achieved at the "B10" location, where at least 77\% overall classification accuracy was achieved. At this location, altitude did not have any significant effect on classification accuracy. These findings corroborate much of what has been concluded through previous research involving using supervised image classification techniques to discriminate between soybeans and weed species in agronomic settings [9-11,23].

The incorporation of a Palmer amaranth density component as part of an eight-class classification system diminished the observed overall accuracy between Palmer amaranth and soybean. In 2016, overall classification accuracy was $16.4 \%(\mathrm{Kc}=0.05)$ and $17.5 \%$ $(\mathrm{Kc}=0.07)$ for the July 14 and August 12 imagery, respectively (Table 3). Due to corruption of the original image file, classification was not possible for the imagery acquired on 28 July 2016. The greatest accuracies with respect to density were achieved at the highest weed density ( 8 plants $\mathrm{m}^{-2}$ ) for Palmer amaranth, while the best classification of soybean occurred at weed densities of 1 plant $\mathrm{m}^{-2}$. This is of note because it may indicate that as Palmer amaranth weed density increases, so does the accuracy at which the classifier can correctly identify Palmer amaranth. In turn, the best supervised classification accuracy of soybean occurs at the lowest weed density, where spectral mixing between the two species would also be minimized. Spectral mixing results in inaccurate spectral classification because the pixel value takes in to account the presence of two of more classes within the pixel with respect to the proportion of the pixel they occupy [24].

Overall accuracies from the 2017 studies were better than those observed in 2016, but errors of at least $65 \%$ were still present in those classifications. At the "B8" location in 2017 , accuracies were $35 \%\left(K_{c}=0.25\right), 11.8 \%\left(K_{c}=-0.01\right)$ and $25 \%\left(K_{c}=0.14\right)$ for the imagery from 6 July, 20 July and 3 August, respectively (Table 3). Similar to observations in 2016, the best species-specific accuracies for Palmer amaranth were obtained at the highest weed density of 8 plants $\mathrm{m}^{-2}$, while the best soybean accuracy was obtained at the lowest weed density of 1 plant $\mathrm{m}^{-2}$. The accuracies observed at the "B10" location were less than those at the "B8" location, and no straightforward trends were observed with respect to imaging date and classification accuracy (Table 9). On the first imaging date (9 June), the highest overall accuracy was observed at $26 \%(\mathrm{Kc}=0.16)$. Accuracies of $25 \%(\mathrm{Kc}=0.16)$ and $15 \%(\mathrm{Kc}=0.03)$ were obtained in the subsequent imaging dates of June 27 and July 11. Discrimination of Palmer amaranth was best at the highest weed density of 8 plants $\mathrm{m}^{-2}$ similar to the other field in 2017. Unlike in the other two studies where soybean discrimination was best at the lowest Palmer amaranth weed density, soybean classification accuracy was similar across a range of Palmer amaranth weed densities (Table 9). The highest overall accuracies for both studies in 2017 were observed at the earliest imaging dates (9 June, 6 July), suggesting that temporal effects may influence the ability of the classifier to discriminate between the two species at the weed densities tested. This trend was not apparent in the 2016 imagery, with accuracy observed in the July 14 imagery being only slightly less than the accuracy observed in the 12 August imagery. In early season, when the plants are small and their proportion of the total number of the pixels in the imagery is small, it may be easier to discriminate between the two species. 


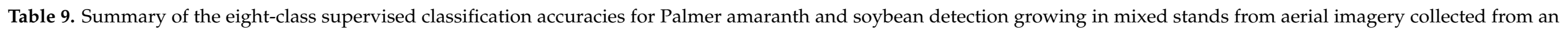
altitude of $15 \mathrm{~m}$ at two separate fields at Rocky Mount, NC in 2016 and 2017.

\begin{tabular}{|c|c|c|c|c|c|c|c|c|c|c|c|c|c|c|c|c|c|c|c|}
\hline \multirow{3}{*}{ Field } & \multirow{3}{*}{ Date } & \multicolumn{8}{|c|}{ Palmer Amaranth } & \multicolumn{8}{|c|}{ Soybean } & \multirow{3}{*}{$\begin{array}{c}\text { Overall } \\
\text { Accuracy } \\
(\%)\end{array}$} & \multirow{3}{*}{ Kc } \\
\hline & & \multicolumn{2}{|c|}{1 Plant $\mathrm{m}^{-2}$} & \multicolumn{2}{|c|}{2 Plants $\mathrm{m}^{-2}$} & \multicolumn{2}{|c|}{4 Plants $\mathrm{m}^{-2}$} & \multicolumn{2}{|c|}{8 Plants $\mathrm{m}^{-2}$} & \multicolumn{2}{|c|}{1 Plant $\mathrm{m}^{-2}$} & \multicolumn{2}{|c|}{2 Plants $\mathrm{m}^{-2}$} & \multicolumn{2}{|c|}{4 Plants $\mathrm{m}^{-2}$} & \multicolumn{2}{|c|}{8 Plants $\mathrm{m}^{-2}$} & & \\
\hline & & $\mathbf{U A}^{\mathbf{a}}$ & PA & UA & PA & UA & PA & UA & PA & UA & PA & UA & PA & UA & PA & UA & PA & & \\
\hline \multirow{5}{*}{ B8 } & 14-July-16 & 0 & 0 & 11 & 11 & 10 & 14 & 20 & 25 & 57 & 27 & 10 & 8 & 25 & 25 & 11 & 13 & 16 & 0.05 \\
\hline & 12-August-16 & 0 & 0 & 0 & 0 & 25 & 40 & 22 & 40 & 60 & 21 & 0 & 0 & 0 & 0 & 33 & 38 & 18 & 0.07 \\
\hline & 6-July-17 & 30 & 43 & 22 & 33 & 43 & 43 & 40 & 36 & 22 & 18 & 38 & 27 & 33 & 30 & 50 & 56 & 35 & 0.25 \\
\hline & 20-July-17 & 0 & 0 & 0 & 0 & 11 & 17 & 40 & 50 & 0 & 0 & 11 & 8 & 10 & 7 & 13 & 20 & 12 & -0.01 \\
\hline & 3-August-17 & 0 & 0 & 11 & 25 & 11 & 17 & 40 & 36 & 20 & 13 & 25 & 20 & 57 & 33 & 38 & 27 & 25 & 0.14 \\
\hline \multirow{2}{*}{ B10 } & 27-June-17 & 0 & 0 & 30 & 60 & 33 & 50 & 56 & 31 & 22 & 18 & 33 & 18 & 30 & 27 & 22 & 25 & 25 & 0.16 \\
\hline & 11-July-17 & 0 & 0 & 0 & 0 & 40 & 44 & 33 & 30 & 13 & 7 & 14 & 6 & 13 & 14 & 0 & 0 & 12 & 0.03 \\
\hline
\end{tabular}

a Abbreviations: UA, user's accuracy; PA, producer's accuracy; Kc, overall kappa statistic. 
As previously observed, varying weed density reduced the overall classification accuracy. When using a maximum likelihood classifier, the introduction of weed density diminishes the classification accuracy. There has been little previous work performed to investigate the feasibility of classifying at the species level based on a surrounding plant density, but Gray et al. [12] did note that the ability for a supervised classification to discriminate between soybean and several weed species using hyperspectral imagery was dependent upon the surrounding weed density and varied with the weed species and density present. Classification accuracies ranged from 8 to $79 \%$, with accuracy increasing as weed density increased. Therefore, much of the same density dependency on the accuracy of classification observed by Gray et al. [12] was observed in this research as well.

\section{Conclusions}

In conclusion, while bands 4 and 5 would appear the most reliable for species detection between Palmer amaranth and soybean at various weed densities, all wavebands utilized in this study demonstrated some functionality in species discrimination. Previous research identified similar bands as those utilized in this research, 490-500 and $600-700 \mathrm{~nm}$, as being particularly useful for species discrimination [12-14]. In addition, Huang et al. [25] identified wavelengths of 400-500, 650-690, 730-740 and 800-900 $\mathrm{nm}$ as not only being useful for species detection, but for detecting fine differences that could exist even within species. The wavelengths identified by Huang et al. [16] roughly align with blue, red, red-edge, and NIR wavebands, respectively, that were used in this research. Furthermore, Hermann et al. [26] found wavelengths between 700 and $1200 \mathrm{~nm}$ useful for weed discrimination as well, a range which includes similar wavebands as those utilized by this research which provides further evidence for their utility for species detection. The distinct differences of spectral reflectance exhibited by Palmer amaranth and soybean were further demonstrated with supervised classification. Two-class supervised classification accuracy ranged from 60 to $90 \%$ across all imaging dates. However, accuracy with the eight-class supervised classification was never greater than $25 \%$ across all Palmer amaranth densities. The inverse relationship of decreased accuracy with increased number of classes is evident from other research $[11,16]$. Thus, the classification accuracy of Palmer amaranth and soybean can increase if fewer, distinct classes are utilized. While many findings of this research were parallel to previous research, the efficiency of the spectral imagery collection with a UAV and advanced analysis software is drastically increased [20].

\section{Future Research}

Future research should focus on using the wavelengths between 717 and $840 \mathrm{~nm}$ (NIR and red-edge) for more concrete spectral reflectance differences between the two species across the tested variables. If consistent spectral reflectance differences are found between the species, supervised classification accuracy may increase and exhibit increased accuracy throughout the season and different weed densities. Additionally, research will be necessary to further understand how temporal factors influence spectral reflectance and classification accuracy at the species level both individually and as a function of surrounding weed density.

Author Contributions: All authors equally contributed to the conceptualization, original draft preparation, and review and editing of this manuscript. All authors have read and agreed to the published version of the manuscript.

Funding: This research received no external funding.

Institutional Review Board Statement: Not applicable.

Informed Consent Statement: Not applicable.

Data Availability Statement: The data presented in this study are available on request from the corresponding author.

Conflicts of Interest: The authors declare no conflict of interest. 


\section{References}

1. Soltani, N.; Dille, J.A.; Burke, I.C.; Everman, W.J.; VanGessel, M.J.; Davis, V.M.; Sikkema, P.H. Perspectives on potential soybean yield losses from weeds in North America. Weed Technol. 2017, 31, 148-154. [CrossRef]

2. Owen, M.D.K.; Zelaya, I.A. Herbicide-resistant crops and weed resistance to herbicides. Pest Manag. Sci. 2005, 61, 301-311. [CrossRef]

3. Ervin, D.; Jussaume, R. Integrating social science into managing herbicide-resistant weeds and associated environmental impacts. Weed Sci. 2014, 62, 403-414. [CrossRef]

4. Heap, I. International Survey of Herbicide Resistant Weeds. Available online: www.weedscience.org/in.asp (accessed on 31 July 2021).

5. Schwartz-Lazaro, L.M.; Norsworthy, J.K.; Steckel, L.E.; Stephenson IV, D.O.; Bish, M.D.; Bradley, K.W.; Bond, J.A. A Midsouthern consultant's survey on weed management practices in soybean. Weed Technol. 2018, 32, 116-125. [CrossRef]

6. Evans, J.A.; Tranel, P.J.; Hager, A.G.; Schutte, B.; Wu, C.; Chatham, L.A.; Davis, A.S. Managing the evolution of herbicide resistance. Pest Manag. Sci. 2014, 72, 74-80. [CrossRef] [PubMed]

7. Ford, A.J.; Dotray, P.A.; Keeling, J.W.; Wilkerson, J.B.; Wilcut, J.W.; Gilbert, L.V. Site-specific weed management in cotton using WebHADSS ${ }^{\mathrm{TM}}$. Weed Technol. 2011, 25, 107-112. [CrossRef]

8. Lopez-Granados, F. Weed detection for site-specific weed management: Mapping and real-time approaches. Weed Res. 2010, 51, 1-11. [CrossRef]

9. Medlin, C.R.; Shaw, D.R.; Gerard, P.D.; LaMastus, F.E. Using remote sensing to detect weed infestations in Glycine max. Weed Sci. 2000, 48, 393-398. [CrossRef]

10. Koger, C.H.; Shaw, D.R.; Watson, C.E.; Reddy, K.N. Detecting late-season weed infestations in soybean (Glycine max). Weed Technol. 2003, 17, 696-704. [CrossRef]

11. Gray, C.J.; Shaw, D.R.; Gerard, P.D.; Bruce, L.M. Utility of multispectral imagery for soybean and weed species differentiation. Weed Technol. 2008, 22, 713-718. [CrossRef]

12. Gray, C.J.; Shaw, D.R.; Bruce, L.M. Utility of hyperspectral reflectance for differentiating soybean (Glycine max) and six weed species. Weed Technol. 2009, 23, 108-119. [CrossRef]

13. Everitt, J.H.; Anderson, G.L.; Escobar, D.E.; Davis, M.R.; Spencer, N.R.; Andrascik, R.J. Use of remote sensing for detecting and mapping leafy spurge (Euphorbia esula). Weed Technol. 1995, 9, 599-609. [CrossRef]

14. Everitt, J.H.; Escobar, D.E.; Alaniz, M.A.; Davis, M.R.; Richerson, J.V. Using spatial information technologies to map Chinese tamarisk (Tamarix chinensis) infestations. Weed Sci. 1996, 44, 194-201. [CrossRef]

15. Basinger, N.T.; Jennings, K.M.; Hestir, E.L.; Monks, D.W.; Jordan, D.L.; Everman, W.J. Phenology affects differentiation of crop and weed species using hyperspectral remote sensing. Weed Technol. 2020, 34, 897-908. [CrossRef]

16. Sanders, J.T.; Jones, E.A.L.; Minter, A.; Austin, R.; Roberson, G.T.; Richardson, R.J.; Everman, W.J. Remote sensing for Italian ryegrass [Lolium perenne L. ssp. multiflorum (Lam.) Husnot] detection in winter wheat (Triticum aestivum L.). Front. Agron. 2021, 3, 687112.

17. Sapkota, B.; Singh, V.; Neely, C.; Rajan, N.; Bagavathiannan, M. Detection of Italian ryegrass in wheat field and prediction of competitive interactions using remote sensing and machine learning techniques. Remote Sens. 2020, 12, 2977. [CrossRef]

18. Fernández-Quintanilla, C.; Peña, J.M.; Andújar, D.; Dorado, J.; Ribeiro, A.; López-Granados, F. Is the current state of the art of weed monitoring suitable for site-specific weed management in arable crops? Weed Res. 2018, 58, 259-272. [CrossRef]

19. He, K.S.; Rocchini, D.; Neteler, M.; Nagendra, H. Benefits of hyperspectral remote sensing for tracking plant invasions. Divers. Distrib. 2011, 17, 381-392. [CrossRef]

20. Zhang, C.; Kovacs, J.M. The application of small unmanned aerial systems for precision agriculture: A review. Precis. Agric. 2012, 13, 693-712. [CrossRef]

21. Swinton, S.M. Economics of site-specific weed management. Weed Sci. 2005, 53, 259-263. [CrossRef]

22. Thorp, K.R.; Tian, L.F. A review on remote sensing of weeds in agriculture. Precis. Agric. 2004, 5, 477-508. [CrossRef]

23. Gibson, K.D.; Dirks, R.; Medlin, C.R.; Johnston, L. Detection of weed Species in soybean using multispectral digital images. Weed Technol. 2004, 18, 742-749. [CrossRef]

24. Louargant, M.; Villette, S.; Jones, G.; Vigneau, N.; Paoli, J.N.; Gée, C. Weed detection by UAV: Simulation of the impact of spectral mixing in multispectral images. Precis. Agric. 2017, 18, 932-951. [CrossRef]

25. Huang, Y.; Lee, M.A.; Thomson, S.J.; Reddy, K.N. Ground-based hyperspectral remote sensing for weed management in crop production. Int. J. Agric. Biol. Eng. 2016, 9, 98-109.

26. Herrmann, U.; Shapira, U.; Kinast, S.; Karnieli, A.; Bonfil, D.J. Ground-level hyperspectral imagery for detecting weeds in wheat fields. Precis. Agric. 2013, 14, 637-659. [CrossRef] 